\title{
New Approaches in Urban Water Systems Engineering
}

\author{
Prof. Brigitte Helmreich \\ Technical University of Munich \\ Germany
}

Climate change, urbanisation and demogrpahic changes, and a growing number of emerging pollutants are increasingly stressing urban water supplies. In order to provide safe supply of water and proper sanitation for cities of the future new approaches are needed to address challenges ahead. Selected examples illustrate opportunities in implementing new approaches in urban water systems engineering.

The removal of emerging trace organic compounds (TrOCs) in groundwater, wastewater, surface and drinking water is of increasing interest to reduce potential adverse effects on aquatic life and human health. The research especially focuses on novel treatment concepts for advanced water treatment, in particular for the removal of nutrients, TrOCs and pathogens including antibiotic resistance. These hybrid processes include modified biological technical filters, advanced oxidation processes (UV / peroxide, nanomodified diamond electrodes, ozone), granulated activated carbon, and membrane processes (ultrafiltration, nanofiltration, reverse osmosis), which can be used both for centralized as well as decentralized treatment approaches.

Natural treatment processes, such as riverbank filtration, soil aquifer treatment or biologically-active filters, are used in water treatment for many decades. New approaches focuse on transitioning these passive treatment systems into active processes with predictable water quality. The integration of these natural processes as new engineered concepts does result in a more effective elimination of organic contaminants and pathogens providing an alternative to advanced treatment technologies. Managed aquifer recharge (MAR) systems, such as riverbank filtration (RBF), soil aquifer treatment and artificial recharge and recovery, have been used for decades to improve the availability of localized water supplies by the utilization of less desirable water sources like storm water, impaired surface water and reclaimed water. During infiltration of water through biologically-active porous media, microbial degradation and assimilation is playing a dominant role for the attenuation of organic contaminants as well as pathogens. An innovative Sequential Managed Aquifer Recharge Technology (SMART) concept actively manipulates subsurface conditions and combines two MAR systems in series with an in between aeration step to provide favorable aerobic, carbon limited infiltration in the second system.

Stormwater runoff from impervious surfaces - including the runoff of metal roofs, building facades and roads - is considered a major source of pollution to the environment. Decentralized sustainable urban drainage systems (SUDS) contribute to the decentralized management and treatment of urban stormwater and they have been shown to efficiently mitigate many of the adverse impacts of urbanisation on the natural water cycle. Of the different SUDS currently available, green SUDS have the longest traditions and are the most commonly used option due to their relative simplicity in design and construction. In urban regions, In urban areas, however, there is often too little space for this technology. Therefore, SUDS often must be provided on the smallest possible area by technical drainage solutions like filter substratum channels or shaft systems. The challenge is to provide enough permeability by the devices to prevent backwater and thereby following limitations for the traffic. Coincidental a contamination of the soil and groundwater must be prevented sufficiently, even at high flow rates. 